\title{
Ethics and Floods: A Systematic Review
}

\author{
Veselin L. Mitrović, PhD; Dónal P. O’Mathúna, PhD; Iskra A. Nola, PhD
}

\section{ABSTRACT}

Disaster ethics is a developing field of inquiry recognizing the wide variety of ethical issues confronting various professionals involved in planning for and responding to different types of disasters. This article explores how ethical issues related to floods are addressed in academic literature. The review involved analysis of publications on ethics and floods identified in a systematic literature search of electronic databases that included sociological, biomedical, and geophysical sources. The review methods were guided by the PRISMA Statement on systematic reviews, adapted to this topic area, and followed by a qualitative analysis of the included publications. All articles were analyzed using NVivo software version 11. The qualitative analysis showed that further research is needed on the ethical issues involved in flood disasters. Ethical guidelines are needed for flood planners and responders that are based on the consistent application of well-established ethical principles, values, and virtues to the specific circumstances arising with each flood. Flexibility is required in applying such approaches. The results suggest that interdisciplinary collaboration (sociological, biomedical, geophysical, engineering, and ethical) could contribute significantly to the development of ethics in floods. (Disaster Med Public Health Preparedness. 2019;13:817-828)

Key Words: bioethics, disasters, ethics, floods, social justice, social values, virtues

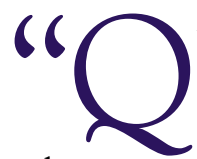
uestions of ethics and aesthetics, of love and beauty, are intertwined with questions about levees, wetland buffers, and sedimentation rates."

Disaster ethics is a developing field of applied ethics that identifies and explores the ethical issues related to disasters. ${ }^{2}$ It includes a number of specialized fields, including preventive ethics, ethics of response, and post-disaster ethics. ${ }^{3-4}$ Preventive ethics, for example, elaborates a set of ethical principles for disaster protocols aimed at preventing disasters, reducing damages or injuries from disasters, and overcoming existing vulnerabilities. ${ }^{5}$ Some preliminary evidence suggests that disaster responders struggle with many ethical issues, yet find few practical guidelines or little useful training. An important step in addressing disaster ethics is to become aware of the ethical issues that can arise in a particular disaster.

This systematic review was designed to identify ethical issues in floods and thereby facilitate the development of relevant guidelines, training, and further research. Floods are increasing in frequency, with the number in Europe more than doubling since $1980 .^{6}$ Globally in 2017 , floods were the most common type of disaster (38.4\% of all disasters), caused the most disaster-related deaths (35\%), and affected most people (59.6\%). ${ }^{7}$ Extreme precipitation has become more commonplace with massive human and economic consequences. ${ }^{8}$ For example, 2 days of heavy rain in 2010 led to $€ 1.2$ billion in damages to Dracénie, a small region in southern France. ${ }^{9}$ Floods accompany other hazards like hurricanes and cyclones, as when a 1999 severe cyclone in Odisha, India had 10,000 flood-related deaths. ${ }^{10}$ Floods impact human health strongly, with disease outbreaks occurring short-term, mortality rates in the first year increasing by up to $50 \%$, and psychological distress lasting much longer. ${ }^{11}$

All disasters raise ethical issues and questions. ${ }^{2,12}$ Floods are distinct in relation to ethics because their occurrence and impact are directly tied to human decisions in ways that other disasters, like earthquakes, volcanoes, and hurricanes, often are not. Several examples from the literature reviewed here illustrate this connection, such as when floods are caused by either the deliberate opening of dams or by human decisions that contributed to their failure. ${ }^{13-14}$ The construction of the world's largest dam, the Three Gorges Dam in China, raised ethical issues because, along with flood management decisions, it displaced 1.3 million people, triggered fatal landslides, and caused environmental problems. ${ }^{15}$ Flooding can be linked less directly to human decisions over 
deforestation, developing wetlands for economic purposes, or building in flood zones. ${ }^{16}$ During floods, redirecting excess water toward some communities and away from others raises intense ethical debates. ${ }^{17}$ For example, rising water levels in 2011 at a dam upstream from Brisbane, Australia led engineers to release water, resulting in US\$5 billion in flood damages, the most expensive natural disaster in Australia's history up to that time. ${ }^{13}$ Although the decision was based on technical information, ethical judgments were involved also.

Flood risk management is responding to climate change, which raises many ethical questions about how this should be done. ${ }^{18}$ If a flood plan includes permanently displacing a particular community for the good of a larger region, this will provoke many questions, including the ethics of such decisions. ${ }^{19}$ After floods, some may want to demolish flooddamaged buildings and rezone floodplains for other purposes, which means justice must be considered. ${ }^{20}$ Individual and community perceptions of the good life lead to ethical dilemmas far beyond those of resource allocation. Therefore, responsible social protagonists should understand the profile of the most vulnerable groups in an affected community. ${ }^{21}$ This is of great importance with floods if the approach promoted is to meet the highest ethical standards.

During disasters, ethics can be perceived and prioritized differently by the impacted community, rescue teams, volunteers, health care professionals, engineers, politicians, and so forth. Ethical dilemmas occur when different professionals engage with different disaster phases, like beforehand during disaster risk reduction (DRR) or flood risk management, or during responses, with triage or recovery. Professionals arrive with different tasks and ethical codes, which can be challenging. Ethical dilemmas arise when concerns about whole populations conflict with individual concerns. How will ethical disagreements be resolved? Does each disaster type need a distinct ethics, leading to, for example, a distinct "flood ethics"? How will ethical principles be applied, or ethical conclusions articulated? These and other concerns motivated this systematic review of ethics and flood to identify how ethical issues are examined in academic literature. The aim was to provide an overview of these ethical issues that makes them easily accessible to those concerned about floods.

\section{METHODS}

\section{Data Sources and Retrieval}

This systematic review aimed to identify relevant studies in the domain of ethical issues in floods. The review methods were guided by the PRISMA Statement on systematic reviews, and the steps involved are shown in a PRISMA flow diagram (Figure 1). ${ }^{22}$ PRISMA, or Preferred Reporting Items for Systematic Reviews and Meta-Analyses, is an evidencebased list of the minimum set of items that should be reported in systematic reviews and meta-analyses (http://www.prismastatement.org). Although the method was developed initially for randomized controlled trials of interventions, it can be used for systematic reviews of other topics. Its guidelines were adapted and followed for this review.

The first search was performed in March 2015 on three electronic databases: the Web of Science (WoS), PubMed, and EBSCO-SocINDEX databases, including articles from 1955 to 2015. The search terms "ethics" AND "floods" were used on all databases. In April 2018, the search was extended to January 2018. The search terms "ethic*" AND "flood*" were used in PubMed and WoS, which more than doubled the number of identified publications. After examining the abstracts, no additional publications met the inclusion criteria compared with searching with "ethics" AND "floods." Therefore, the new search was completed with the original search terms. Another database was included in the new search: Scopus, from inception to January 2018. Figure 1 shows the numbers of articles retrieved from each database.

\section{Data Collection}

The search returned 290 articles, with the distribution between the four databases shown in Figure 1. Of these, 61 were identified in two or more databases. Removal of the additional entries of the same articles left 216 unique articles. Examination of the abstracts identified 154 articles that did not fit the inclusion criteria described in the next paragraph. The remaining 62 articles were read in full, and a further 23 articles excluded, with reasons for each exclusion recorded. This gave 39 included publications.

Inclusion criteria included any type of publication in the selected databases that examined both floods and ethics in substantial ways. Floods resulting from relatively rapid-onset disasters, such as hurricanes, monsoons, cyclones, and torrential rain, were included, but not those due to gradual flooding, like those accompanying sea-level changes. Publications were included if they addressed ethics before, during, or after floods, and addressed any aspect of flooding, including water management and engineering, public health, flood risk management, preparedness, disaster research, sociological issues, flood responses, and environmental ethics. Articles were excluded if floods were mentioned only as examples within a general discussion of disasters or environmental ethics. Also excluded were articles that discussed floods at length, but mentioned ethics only in passing.

\section{Analysis of Findings}

All included articles were uploaded into the qualitative analysis software, NVivo version 11. This software allows identification of "nodes," each being an ethical issue emerging from the literature. Forty-one nodes were identified and organized into 10 broader themes (see Table 1). The authors discussed the themes iteratively, leading to summaries that revealed the connections between each ethical issue and floods. This analysis is presented in detail in the section, Results. 
PRISMA Flow Diagram for Ethics and Floods.

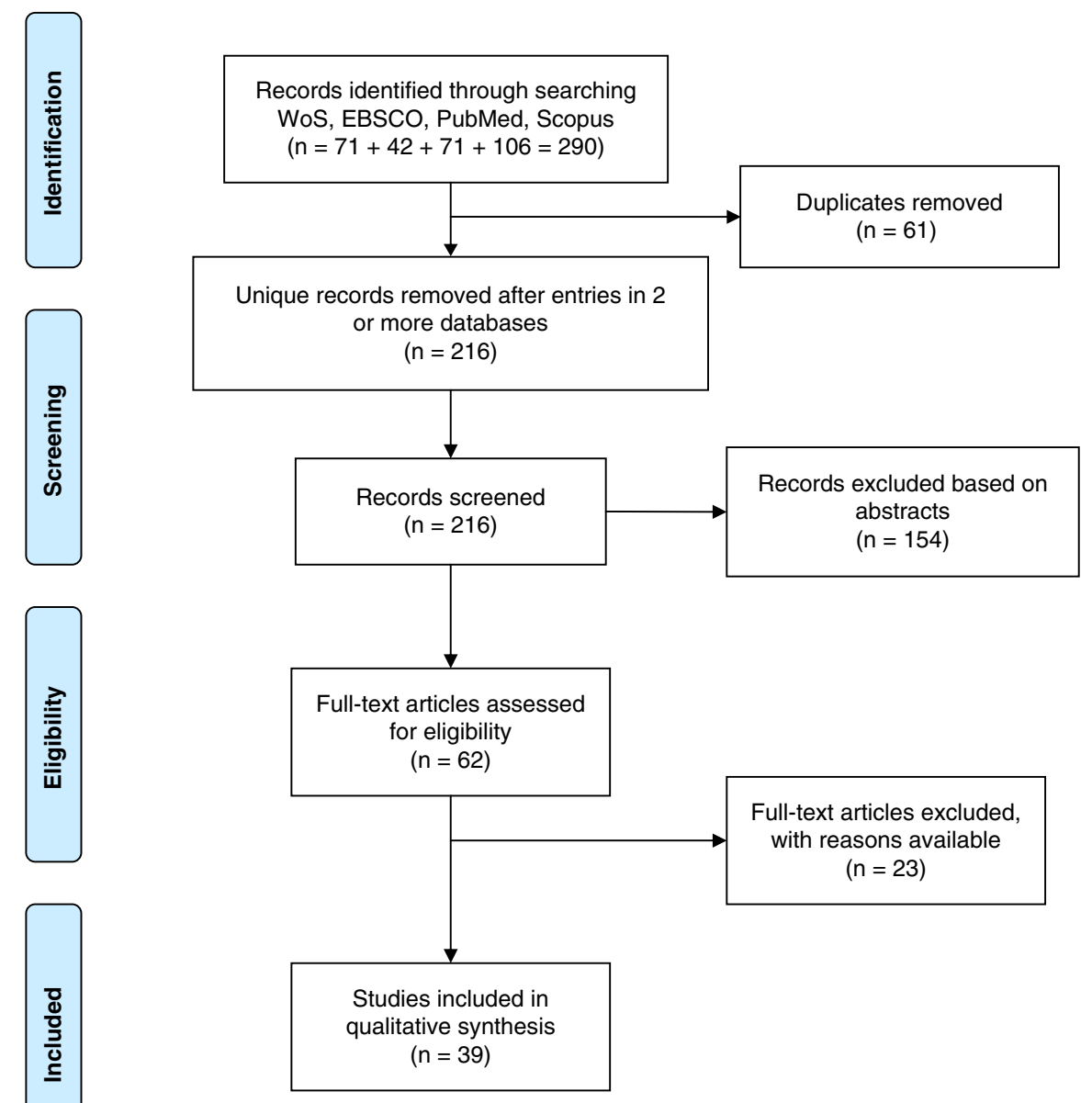

\section{RESULTS}

\section{Scientometric Analysis of the Included Papers}

The review included 39 articles published in various academic fields, including biomedicine, social sciences, geophysics, and engineering. They included research studies, editorials, and ethical analyses. The articles addressed floods from around the world, including Australia, the Caribbean, China, Europe, Honduras, India, Japan, Mauritius, Nigeria, Pakistan, Solomon Islands, and the United States, and some addressed floods in general (Table 2).

\section{Qualitative Analysis of Included Articles}

Software like NVivo allows some quantitative data to be generated, such as the number of articles addressing each ethical theme (see Table 2). Such analyses have limitations because more frequent discussion of an ethical issue does not necessarily mean that it is more significant. Some articles addressed several ethical issues, whereas others focused on fewer, skewing the numerical count. Some subthemes could fit within different themes, such as the balance between short-term and long-term planning relevant to environmental ethics, flood risk management, and addressing vulnerabilities. In spite of these limitations, such data do show the extent to which various ethical themes are discussed in the academic literature reviewed here. The following are the 10 ethical themes arising from this analysis, arranged alphabetically.

\section{Communication}

Communication was identified as critical during floods, with an ethical responsibility to provide information that is "essential, truthful, and useful." 23 Those with expertise have an ethical duty to inform communications both with the public and those managing flood preparations and responses. ${ }^{24}$ Communication should be clear and effective, explaining technical terms well. ${ }^{24}$ This benefits others by preparing people for floods and thereby reducing harm and injuries. ${ }^{25}$ Good communication also should convey care and compassion. ${ }^{13}$ 
Ethics and Floods

TABLE 1

Themes from the Analysis of the 39 Included Publications

\begin{tabular}{|c|c|c|c|c|c|}
\hline & $\begin{array}{l}\text { Number of Included } \\
\text { Publications Discussing }\end{array}$ & & $\begin{array}{l}\text { Number of Included } \\
\text { Publications Discussing }\end{array}$ & & $\begin{array}{l}\text { Number of Included } \\
\text { Publications Discussing }\end{array}$ \\
\hline hemes & Each Theme & Subtheme & Each Subtheme & Factors & Each Factor \\
\hline
\end{tabular}

Communication 23

Autonomy 2

Community engagement and $\quad 13$

empowerment

Cultural values 4

$\begin{array}{llll}\text { Environmental ethics } & 15 & & \\ & \text { Development and sustainability }\end{array}$

Ethical reflection 13

\begin{tabular}{llr}
\hline Flood risk management & 28 & \\
& & Disaster risk reduction (DRR) \\
& Early warning & 6 \\
& Evidence-based & 3 \\
& Uncertainty & 11 \\
& & 7
\end{tabular}

Health and well-being 26

$\begin{array}{lr}\text { Animal health } & 2 \\ \text { Beneficence } & 12 \\ \text { Harm } & 11 \\ \text { Health risks } & 8 \\ \text { Psychological } & 6\end{array}$

Safety

6

Healing 4

Mourning 3

Resilience 2

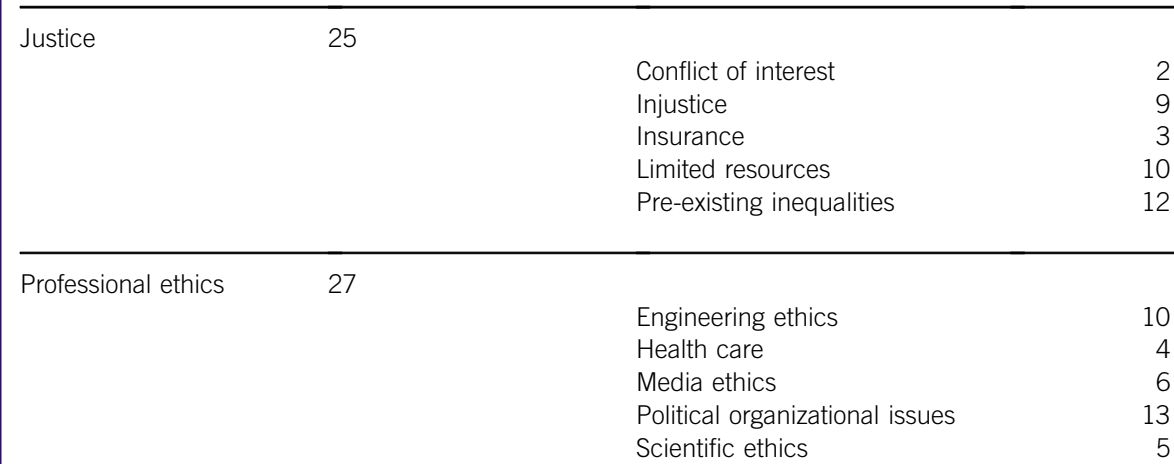

Research ethics 5

Virtue ethics 29

$\begin{array}{lr}\text { Compassion } & 1 \\ \text { Courage } & 4 \\ \text { Honesty } & 13 \\ \text { Humility } & 5 \\ \text { Respect } & 5 \\ \text { Transparency } & 6 \\ \text { Trust } & 5\end{array}$

Vulnerability

15

Refugees and migrants

4

Note: The total number of publications for each theme does not equal the sum of its subtheme column because publications varied in how many subthemes each discussed. 


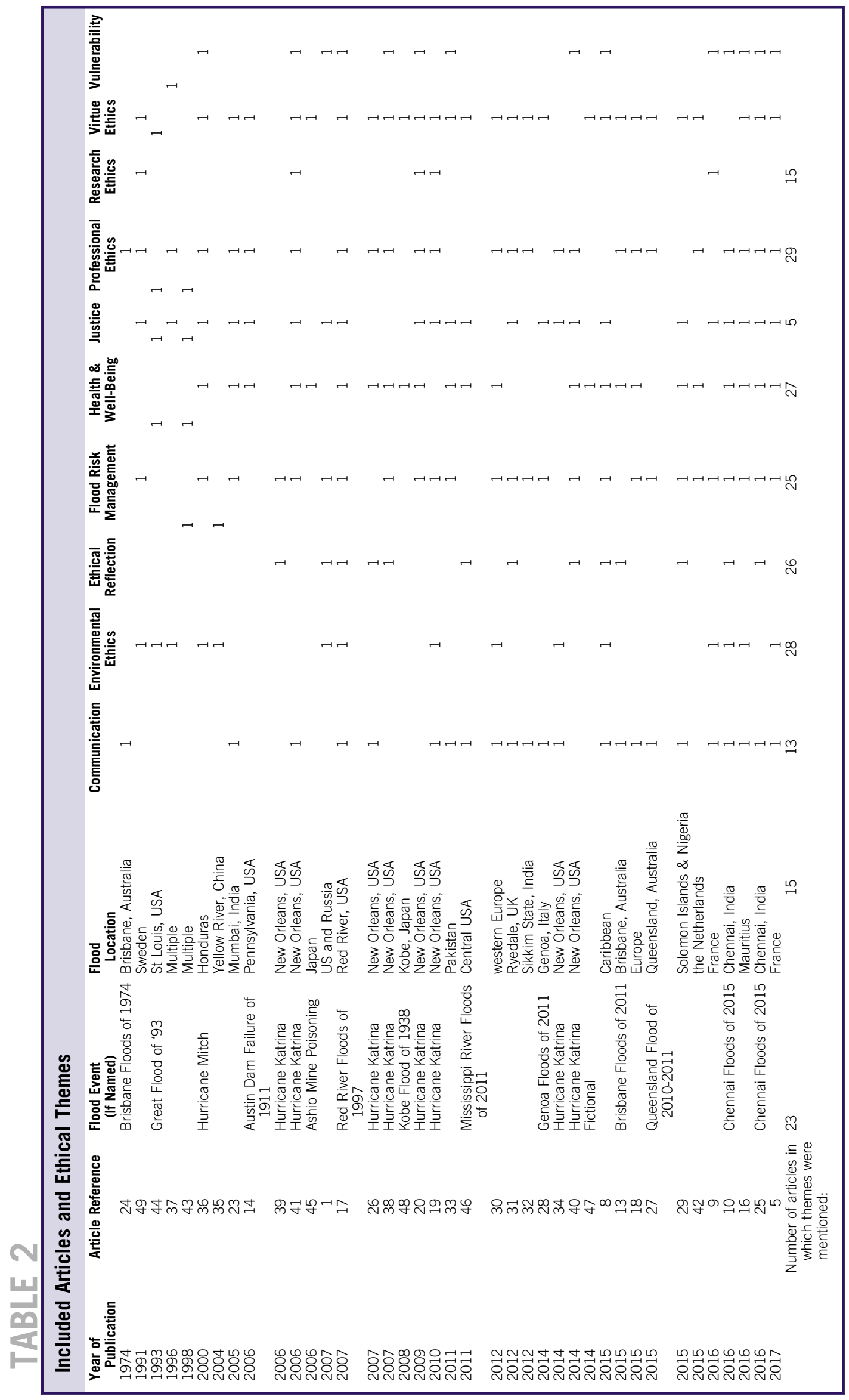


Communication breakdowns have serious consequences, contributing to needless damages and losses, ${ }^{24}$ and can contribute to anxiety. ${ }^{13}$ Poor communication can lead to confusion and conflict between responders. ${ }^{26}$ Communication addresses more than informational needs and includes balancing the risks of false positives and false negatives due to uncertain information. For example, a record-breaking flood was predicted in 1997 for the Red River in North America, but meteorologists feared panic among the public if worstcase scenarios were discussed. ${ }^{17}$ What was called "the most overarching informational failure" with Hurricane Katrina was how storm flooding risks were misinterpreted and miscommunicated, leading to a false sense of security about the flood defenses. ${ }^{19}$ Similar problems were identified by the commission investigating the 2010-2011 floods in Queensland, Australia. ${ }^{27}$

These factors imply that everyone has an ethical responsibility to inform themselves about their flood risks. Creative approaches to communicating flood risks are being developed, like in Munich, Germany, where a public park is allowed to flood regularly as a "vaccine against the illusion of absolute safety." ${ }^{8}$ Social media is increasingly used during floods to provide rapid communication, although concerns exist about the accuracy of the information provided this way ${ }^{28}$ and potential negative effects from identifying flood responders working in insecure settings. ${ }^{29}$

Three subthemes were identified within communication. One was how the ethical principle of autonomy underlies the requirement to provide accurate information and thereby allow decision-makers to make informed decisions. ${ }^{17}$ The second subtheme addressed community engagement within communication. This related to a paradigm shift within flood risk management from a "top-down" approach to communication, where experts provide information to citizens, ${ }^{5}$ to active engagement between experts and citizens throughout planning. ${ }^{30}$ Authentic collaboration develops trust and allows better communication. ${ }^{31}$ Community engagement requires "hard work, sincerity, and honesty," but is ethically valuable, ${ }^{32}$ especially to identify important local knowledge and cultural values. ${ }^{9,16}$ The third subtheme points to the importance of cultural values in communication. ${ }^{9}$ Cultural differences contribute to ethical conflicts, particularly in stressful settings. ${ }^{33}$ For example, after Hurricane Katrina, wealthier people measured success in terms of work accomplishments and economic achievements, whereas poorer people measured success through survival and relationships. ${ }^{26}$ Understanding such cultural values is critical for effective communication in multicultural situations. $^{34}$

\section{Environmental Ethics}

The literature linked flood ethics with broader concerns about environmental ethics. Human interactions with the environment have been classified as Mastery over nature, Stewardship of nature, Partnership with nature, and Participation in nature. ${ }^{30}$ Similar divergent views are found between Confucianism and Taoism in Chinese cultures. ${ }^{35}$ These divergent approaches influence ethical issues, with Mastery emphasizing building dams and dikes to control rivers, while Stewardship holds that control is neither feasible nor good for the environment. ${ }^{16,30}$ Environmental ethics often overlapped with justice, a separate theme in this analysis. ${ }^{34}$ Thus, flood damage from hurricanes in Central America was traced to human decisions that led to deforestation, soil degradation, and chaotic urbanization. ${ }^{36-37}$

Development and sustainability was a subtheme highlighting how emergency flood responses should be balanced with sustainable development. ${ }^{16}$ Ethical issues arise in determining whether assistance should focus on the immediate needs after floods, or on reducing exposure to future risks. ${ }^{36}$ Preventive ethics is one approach that integrates post-flood recovery programs with measures to reduce flood vulnerabilities and socioeconomic inequalities through building back better.,

\section{Ethical Reflection}

Ethical reflection is sound decision-making that ensures the right thing is done for the right reasons. ${ }^{38}$ Flood management requires technical knowledge but is incomplete without ethical knowledge to maximize public goods, minimize flood harms, and make flood mitigation and management systems fair and equitable. ${ }^{1,25}$ Ethical reflection develops the capacity to act responsibly toward others, particularly the vulnerable. $^{13,38}$ Some organizations, like the Red Cross, use specific ethical principles to guide ethical reflection that also takes an account of contextual details. ${ }^{29}$ Others advocate the development of ethics guidelines for flood management. ${ }^{10}$ Cases are used to promote ethical reflection using relevant frameworks. ${ }^{17}$ Ethical reflection can be complex and messy when undertaken with imperfect knowledge and in the midst of uncertainty. ${ }^{39}$ Professionals who are less familiar with value conflicts may need to develop ethical reflection skills, along with their "moral imagination" and aesthetic sense. ${ }^{31}$

\section{Flood Risk Management}

Flood risk management covers several aspects of reducing the likelihood and impact of floods. The ethical issues here were frequently raised. Better preparedness was widely held to bring better responses, generating an ethical obligation to prepare well so that communities and facilities become "resilient, responsive, and adequately equipped." 25 In contrast, poor flood risk management has harmful consequences, ${ }^{40}$ such as when commercial and bureaucratic interests are placed over individuals' well-being. ${ }^{41}$ Ethical aspects of centralized risk management are rarely addressed because of implicit assumptions over who decides what flood risks are acceptable. ${ }^{31}$ The prevailing hierarchical model assumes that risks should be assessed scientifically, that 
statutory bodies should manage risks, and that those living with flood risks should conform to whatever others decide. ${ }^{31}$ This devalues the input of those living with flood risks. ${ }^{16}$ Involving local communities helps address cultural issues, which can make strategies more effective. ${ }^{9}$

The flood risk management theme overlapped with the environmental ethics theme, particularly on whether to fight rivers and control floods, or work with nature. ${ }^{30}$ Management strategies based on mastering nature have been traced to "enthusiasm and faith in the superiority of man's rationality" 18 and confidence in making regions "climate-proof." 42 These result in higher risks, with large housing projects throughout Europe built behind river flood defenses on well-known floodprone areas. ${ }^{18}$ Other management strategies are now being developed based on adapting to flood risk, accepting uncertainty, and rejecting claims of absolute protection from floods.

Uncertainty was a subtheme that characterized flood risk management. ${ }^{9}$ Ethical decision-making always involves imperfect knowledge, such as when benefits should be distributed appropriately in light of uncertainty. ${ }^{17}$ This leads to an ethical obligation to plan with flexibility and allow new information to change plans. ${ }^{19}$ When uncertainty is not communicated adequately, the autonomy and beneficence of those impacted by floods is compromised. ${ }^{17}$ DRR was another subtheme within flood risk management. When DRR reinforces "command and control" or "top-down" approaches, the public is treated as passive recipients of information rather than active contributors. ${ }^{16}$ Engaging communities within DRR strategies can reduce flood risks and harms, ${ }^{5}$ such as how Odisha, India, reduced flood fatalities from around 10,000 in 1999 to around 24 in 2013, largely due to introducing DRR systems. ${ }^{10}$ The ethical obligation to manage floods according to the best available evidence was another subtheme. Poor flood management occurred when manuals and procedures were not updated. ${ }^{19,27}$ Flood risk management should be science-based but also involves policy decisions that introduce human values. ${ }^{31}$ Professionals must also be able to recognize whether various pressures attempt to bias their decisions in unethical ways. ${ }^{23}$ The final subtheme here was early warning to reduce harm and preserve life. ${ }^{16}$ Delayed warnings about Hurricane Katrina ${ }^{20}$ and the 1997 Red River floods ${ }^{17}$ caused additional hardship for residents of flooded areas.

\section{Health and Well-Being}

Health and well-being was a theme bringing together several related subthemes. The ethical principle of beneficence maximizes benefits over risks and harms and motivates people to help after floods. ${ }^{41}$ Flood responders should ask themselves regularly whether their actions are beneficial and to whom. ${ }^{43}$ Professional codes of ethics, like those of the American Society of Civil Engineers, emphasize this, stating, "Engineers shall hold paramount the safety, health and welfare of the public. ${ }^{40}$ Beneficence addresses more than practical utility, because joy can be experienced in the midst of suffering by helpers and those helped. ${ }^{44}$ Flood risk management strategies can benefit people and the environment, like when they include recreational areas that promote human well-being. ${ }^{18}$ Social support is an important element of helping people after floods, both for survival and recovery. ${ }^{16,41}$ Beneficence should be based on the needs of those impacted by floods and take into account justice. ${ }^{5}$ Questions must be asked about who benefits and when. ${ }^{36}$ Beneficence not only concerns individuals, but also must address social goods. ${ }^{17}$ This can lead to ethical dilemmas, like when one area is flooded to reduce the harm to another area, or when present needs are relieved at a cost to future generations. ${ }^{36}$

Another subtheme was harm minimization, with "do no harm" a core ethical obligation. ${ }^{13}$ Practices that do more harm than good are unethical. ${ }^{45}$ Harm can occur in many ways, including physically, psychologically, economically, environmentally, socially, and more. ${ }^{41}$ Particular attention should be given to those with heightened vulnerabilities and to interventions causing unintended harm. ${ }^{38}$ Difficult ethical dilemmas arise when some people are harmed to reduce others' harm, as when dam spillways are opened. ${ }^{46}$

The subtheme, health risks, pointed to an ethical obligation to prepare well for floods. Medical and public health systems should be prepared for disasters, access should be equitable and culturally sensitive, and practice should be evidencebased. ${ }^{33}$ When done well, health risks can be reduced. ${ }^{25}$ Floods are particularly challenging with health risks because of displacement, waterborne diseases, release of sewage and pollutants into water, and diminished access to fresh food and water. ${ }^{8}$ Justice overlapped here with its concern for vulnerable populations, such as those in wheelchairs, elderly living alone, those with mental illnesses, ${ }^{25}$ and particularly the poor. ${ }^{23}$ Safety is related to harm and should be central to flood risk management. ${ }^{5}$ Investigations into Hurricane Katrina have criticized how safety was not a top priority in building levees around New Orleans. ${ }^{40}$ The failure of the Austin Dam in 1911 was largely due to unethical decisions that compromised the dam's integrity and cost 78 people their lives. ${ }^{14}$ In determining how safety is viewed and addressed, both local communities and experts should be involved. ${ }^{30}$

Psychological impacts of flood are significant, ${ }^{16}$ and the related ethical issues constituted their own subtheme. Posttraumatic stress and depression are commonly found after floods and other disasters. ${ }^{41}$ However, many people have mental health and social problems before floods, which may be exacerbated by floods. ${ }^{44}$ Ethical dilemmas arise over how to prevent and treat these conditions as evidence is lacking on the effectiveness of interventions, and research on them raises particularly challenging ethical issues. ${ }^{41}$ The psychological impacts point to the importance of compassionate support after floods. ${ }^{13}$ Within this subtheme, 3 factors 
centered around recovery. Mourning should be permitted, as people experience losses over and over. ${ }^{47}$ People should be given time to mourn, including informally by talking to friends and colleagues. ${ }^{13}$ The second factor was healing, with responders needing to find an ethical balance between remembering and forgetting, ${ }^{47}$ because finding positive meaning in the face of floods can be key. ${ }^{48}$ Narratives help here but can be difficult to decipher. ${ }^{41}$ The third factor is resilience, or what was called "emotional levees." ${ }^{44}$ Social support and networking are important here, especially in caring for the vulnerable, such as the elderly, disabled, and children. ${ }^{16}$

A final subtheme mentioned by 2 authors was animal health because of the close connection in some cultures between animal and human health. ${ }^{25}$ Sometimes, animals are part of the family, and people seek help for them after floods. On the other hand, some animal illnesses spread to humans and this should be addressed. ${ }^{25}$ When animals die, the food supply is affected, raising ethical questions about whether they should be rescued or left to die. ${ }^{8}$

\section{Justice}

Justice linked into many themes as an important ethical principle providing context for balancing benefits and harms, and addressing autonomy. ${ }^{17,28}$ Justice is concerned with fairness, but its practical application is often controversial and disputed. For example, decisions made to allow one region to flood to protect another region on the basis of larger net social benefit are controversial, sometimes leading to civil unrest. ${ }^{17}$ To minimize these effects, planning and management should be just, needs-based, equitable, and transparent. ${ }^{25}$ In pursuing science-based flood management, a naïve scientism can develop which conflicts with social justice. ${ }^{31}$ Even policies to reduce flood-prone housing involve ethical value judgments and are never completely neutral. ${ }^{5}$ According to Rawls's theory, justice calls for the preferential treatment of the poor. ${ }^{36}$ This is particularly important in research, so that risks and benefits are justly distributed, ${ }^{41}$ as it should with the distribution of information. ${ }^{43}$

One subtheme here was conflict of interest, where something other than need determines how resources are allocated. For example, a mining company offered a large donation to flood relief in the Solomon Islands, but wanted more funds allocated to regions close to their mines. ${ }^{29}$ The Red Cross determined it would be unethical to accept this donation, partly because those regions were not the most needy. ${ }^{29}$ In 1911, the state senator for the Austin Dam area was also the dam owner's attorney, setting up another conflict of interest. ${ }^{14}$

Injustice was a subtheme identifying ways that resources were distributed unethically. ${ }^{16}$ Sometimes, relief was deliberately denied certain people, involving discrimination, disrespecting people's dignity, and potentially violating human rights. ${ }^{33}$ Injustice can occur less overtly, as in how those over 75 years made up almost half of the fatalities during Hurricane Katrina. ${ }^{40}$ Similarly, the poor, minorities, and those with mental illnesses suffer disproportionately in flooding. ${ }^{41}$ Such vulnerabilities make social justice and ethics discussions crucial with floods. ${ }^{1}$ Past injustices can contribute to current flooding tragedies. For example, the 1960s deforestation by US-based banana companies left Central America more prone to later hurricane-related flooding. ${ }^{36}$

Another subtheme was preexisting inequalities. Both in highincome countries like the United States, ${ }^{41}$ and low-income countries like India, ${ }^{16}$ the poor suffer disproportionately from flood damage. Sometimes poverty pushes people to live in more flood-prone areas. ${ }^{37}$ The gap between rich and poor nations continues to grow, requiring approaches to justice that actively improve the situations of the more vulnerable. ${ }^{17}$ Floods can provide opportunities to redress preexisting inequalities $^{34}$ through effective risk reduction and explicit efforts to redress disparities. ${ }^{9}$

Addressing limited resources ethically was another subtheme. In building flood defenses around New Orleans, the US Congress sought to minimize costs that impacted safety. ${ }^{40}$ After floods, the need for resources is immense. ${ }^{29}$ Typically, the most ethical approach is to prioritize individuals' wellbeing. ${ }^{41}$ The resulting ethical dilemmas are intense and make it important to involve local stakeholders in decision-making and policy-making. ${ }^{5}$

Flood insurance was a specific ethical dilemma within justice. Insurance is traditionally based on the view that the burdens of a few should be spread more widely so that more people carry a lighter load. ${ }^{43}$ However, as more accurate data on flood risk become available, insurance companies may want to remove high-risk individuals from their client pool. This would leave only lower-risk individuals eligible for flood insurance, but as they understand their risk better, those at low risk will be less likely to purchase insurance. ${ }^{43}$ Many do not purchase flood insurance, even when governments urge this, making it unclear how just flood insurance schemes should be created. ${ }^{17}$

\section{Professional Ethics}

This theme combined the ethical obligations of several professional groups involved in floods. Professional ethics are important for credibility, particularly with societal and environmental issues. ${ }^{32}$ When this is lacking, unethical practices undermine recovery and the willingness of others to help. ${ }^{20}$ Validated competency is an important component of professional ethics. ${ }^{41}$ Both scientific rigor and professional ethics are needed for successful water management. ${ }^{43}$ The credibility of each profession requires that ethics be addressed diligently and effectively. ${ }^{32}$ 
Engineering ethics was a prominent subtheme. Engineers' professional duty to benefit the community comes before their responsibility to the profession or other private interests. ${ }^{24}$ The civil engineers' code of ethics makes public safety and welfare the top priority, although this was found to have been neglected in constructing flood defenses around New Orleans, ${ }^{40}$ and by dam operators in the 2011 Queensland, Australia floods. ${ }^{27}$ As professionals, engineers need to guard against extrapolating from past experiences into new settings, overlooking their methods' limitations, and failing to keep current because these all have serious ethical implications. ${ }^{19}$ Some engineers should be involved in politics or with politicians to promote better flood-related policy decisions. ${ }^{24}$ Engineers should be aware of the ethical and philosophical debates discussed under the themes of environment ethics and flood risk management because these directly impact on ethical decision-making. ${ }^{18,30,43}$ Ethical reflection is key, which is best modeled by mentors who are committed to ethical reflection and practice. ${ }^{40}$

Media ethics was another subtheme. The media can do much good when they disseminate accurate information, but cause harm with biased or sensational stories. ${ }^{16}$ Selective reporting can bring more attention to one region, with others being neglected, or to an emphasis on short-term relief with long-term development being overlooked. ${ }^{10}$ The media's considerable power is seen in how they can attribute blame to individuals or groups. ${ }^{27}$ During Hurricane Katrina, claims of "civil unrest" and "urban warfare" had little supporting evidence, with the resulting damage difficult to correct. ${ }^{27}$ On the other hand, media reports of people helping one another can lead to positive community spirit and hope. ${ }^{13}$

Decisions about flood risk management have political dimensions and point to politicians' ethical responsibilities. ${ }^{16}$ Politicians often make ethical decisions about allocating resources. ${ }^{19,42}$ However, they can have conflicts of interest, which may influence their decisions unethically. ${ }^{14,26}$ Engagement with local communities and local elected officials is crucial. ${ }^{5}$ The literature included here was mostly critical of politicians. For example, political corruption was a major problem during and after Hurricane Katrina, with authors noting that unethical leadership leads to unethical practices throughout organizations. ${ }^{20,34}$ At the same time, political failures can lead to reform and better policies. ${ }^{27}$

The professional ethics of scientists impacts how they proceed when data are lacking, or how they allow data to be used or misused by others. ${ }^{49}$ Scientists presenting information to the public and policy-makers must make judgments about the risks of false negatives and false positions, which are ultimately ethical decisions. ${ }^{17}$ Scientists can come under pressure to present their data in ways favoring other interests, giving rise to further ethical dilemmas. ${ }^{23}$
The included articles had little to say about health care professional ethics, although this is addressed elsewhere regarding disasters. ${ }^{2}$ One included article mentioned the ethics of crisis counseling where professionals encounter problems that exceed their area of specialization and competence. ${ }^{44}$ Health care systems have ethical duties to prepare their professionals for floods (by providing appropriate training and resources) and to provide them with mental health services after floods. ${ }^{25}$ In the midst of crises, health care managers make difficult ethical decisions impacting those in their care, for which they often have little guidance and must rely on their consciences. ${ }^{38}$

\section{Research Ethics}

This theme arose less frequently than anticipated. Research is needed into the psychological impacts of floods and how to address them, which raises the usual research ethics issues to ensure participants are respected, fully informed, not harmed and recruited justly. ${ }^{41}$ Confidentiality is particularly important, suggesting that group interviews are rarely appropriate in psychological research. ${ }^{41}$ Even those in powerful positions expect absolute confidentiality in research participation. ${ }^{20}$ Sometimes, doing research immediately after floods is not ethical because floods deeply impact people who should be allowed to focus on recovery. ${ }^{9}$ The data generated by scientific research can lead to ethical debates over ownership and how data should be used beneficially. ${ }^{49}$ In general, an ethical responsibility exists to ensure that research results are used practically. ${ }^{19}$

\section{Virtue Ethics}

Virtue ethics was a common theme, exemplified by people acting "wisely ... and even courageously." ${ }^{38}$ Virtues engage with questions of conscience, ${ }^{19}$ such as when the virtue of courage leads someone to speak the truth even with negative consequences. ${ }^{14}$ The literature often criticized those lacking certain virtues, such as when people took advantage of distressful situations for personal gain. ${ }^{20}$ Altruism was a virtue one author claimed was rarely visible in today's leaders, leading to questions about how this and other virtues could be nurtured. ${ }^{8}$ Seeing people act virtuously, as when they are compassionate, can motivate others to follow that example. ${ }^{13}$ Virtue ethics uses narratives to instill virtues, providing one means of transforming horrible flood narratives into something encouraging. ${ }^{48}$

Each subtheme here focused on a specific virtue. Compassion was defined as the "capacity to act responsibly toward the 'other" and viewed as central to all ethical decisionmaking. ${ }^{13}$ Courage helps people act on their belief that peoples' well-being should be prioritized. ${ }^{41}$ For example, a Brisbane branch of an international company broke with its policy of not paying employees who could not work during the 2011 Brisbane flood, demonstrating compassion and moral courage. ${ }^{13}$ 
Honesty was the most frequently mentioned virtue and included admitting when interventions and policies do not work because this avoids wasting resources. ${ }^{49}$ Honest appraisals of flood risks help avoid false expectations. ${ }^{17}$ Honesty is crucial to maintain credibility. ${ }^{32}$ Impartiality is an aspect of honesty where people commit to make judgments based on evidence and needs. ${ }^{46}$ Thus, impartiality is a core ethical principle for the Red Cross, where anything that compromises the perception of impartiality is viewed as unethical. ${ }^{29}$ Dishonest reporting can lead to harm, as was noted under media ethics. ${ }^{27}$ Failing to fulfill commitments, sometimes called donor fatigue, also can reflect a lack of honesty. ${ }^{36}$ After Hurricane Katrina, harm arising from dishonesty was identified, including individuals filing false damage claims, contractors taking money without doing the work, and politicians being unable to account for funds. ${ }^{20}$

Humility was an important virtue, especially when working with unknowns and uncertainties, and for admitting when approaches do not work. ${ }^{32,49}$ The change in attitude toward nature from one of mastery to cooperation expresses humility. ${ }^{30}$ This involves dismissing the "myth of absolute protection." 18 Humility links with honesty in that open communication of experiences can invoke humility and gratitude, leading to generosity toward others. ${ }^{13}$

Respect for others was another ethical virtue. The Red Cross's ethical code is based on the view that all humans are of equal worth and that everyone has a duty to help those in need. ${ }^{29}$ Similarly, the Universal Declaration of Human Rights states that all humans have "inherent dignity" and "inalienable rights." ${ }^{33}$ This should lead to people developing the virtues of respecting others ${ }^{46}$ and valuing their dignity. ${ }^{13}$

The virtue of transparency promotes fairness and accountability. ${ }^{25,29}$ It leads to openness about the uncertainty of some information in flood planning, and the importance of impartial decision-makers. ${ }^{46}$ Transparency is important in ethical decisions, especially when people hold different positions, and points to why people should be able to explain the reasons why certain decisions were taken. ${ }^{39}$

A core element of virtue ethics is trust, which can be difficult to win. ${ }^{44}$ When authorities are believed to lack core virtues, people's trust quickly disappears. ${ }^{16}$ In contrast, trust is won through a history of virtuous behavior. ${ }^{29}$ It is gained by working together and sharing common experiences. ${ }^{31}$ During crises, trust must be nurtured, for which good communication and empowering community members are important. $^{28}$

\section{Vulnerability}

The final theme was vulnerability, giving an ethical obligation to care for those at particularly high risk of harm from floods. ${ }^{16}$ Heightened vulnerability arises for those over 75 years, minorities, the poor, and those with mental illnesses. ${ }^{10,40-41}$ Those requiring wheelchairs and other medical equipment are more vulnerable during floods, as are residents in jails, orphanages, and other institutions. ${ }^{25}$ A complex interplay of social, economic, and natural causes increases or decreases vulnerabilities. ${ }^{1}$ Yet, in some situations, the vulnerable are actively discriminated against. ${ }^{10}$ This should be seen as unethical, and active steps taken to overcome vulnerabilities. ${ }^{17}$ Recovery periods can be used as opportunities to address inequities and overcome vulnerabilities, and this should be an ethical priority. ${ }^{5}$

A subtheme here was concern for refugees. Floods and other disasters lead to many internally displaced persons (IDPs) and refugees. ${ }^{36}$ Environmental changes traditionally led to IDPs who remained within their countries, as when mass migration into cities occurred after one-fifth of China's uplands were flooded in $1994 .{ }^{37}$ In 2010, heavy rainfall led to record flooding in Pakistan, which killed almost 2,000 people, impacted 18 million, and led to millions of IDPs. ${ }^{33}$ However, the scale of floods is leading to increased numbers of refugees crossing borders, for which many regions are unprepared. ${ }^{36}$ Migrants and refugees often live in insecure housing which makes them particularly vulnerable to further harm. ${ }^{10}$ Yet, in many places, no provisions are made for migrants and local officials who may not know how many live in their jurisdictions. This adds an ethical responsibility to include migrants in flood risk management plans.

\section{DISCUSSION}

This systematic review identified 39 included articles addressing ethics in floods. Their analysis led to 10 ethical themes and several subthemes. Some themes, like justice and professional ethics, had been anticipated, but others had not been expected to feature as prominently, like virtue ethics and animal ethics. Some ethical issues were discussed less frequently than anticipated, as with research ethics and health care ethics, although these are discussed elsewhere for disasters generally. ${ }^{2,50}$

Social justice was a broad area of ethical concern, emerging in 25 of the 39 included articles. This theme was identified as strongly influencing other ethical themes. Comparative studies have shown that the same flood has different impacts within the affected population based on varying levels of resilience. ${ }^{51-52}$ This capacity is related to social inequality, vulnerability, and susceptibility within societies. ${ }^{53}$ The enormous economic and human toll of floods alerts us to the need to constantly develop and reevaluate ethical guidelines. Disasters trigger an emphasis on promoting better survival rates and quicker recoveries. However, mere survival is usually not enough for those who live directly with the consequences of floods and disasters. Recovery that focuses only on the built environment could inadvertently lead to 
undesirable outcomes or unethical means to goals, especially for those with preexisting inequalities. Rebuilding flooded areas to restore pre-flood conditions is not as beneficial as building back better. Doing so requires careful reflection on ethical issues, and ethical guidelines should take into account the resilience and vulnerability of different groups within society. The dignity and equal rights of all should be recognized and protected in flood-prone societies.

Many articles called for increased training in ethical reflection and decision-making for the various professionals working on floods. The goal, according to one included article, seems simple: Do the right thing. ${ }^{38}$ Achieving this is not so simple. "Specifically, morally sound decisions involve good information, sound values, engagement of appropriate stakeholders, and the ability to make decisions. Seeking morally sound decisions is complex because situations often require decisions by a group (underpinned by individual decisions). These are made in the fog of incomplete or contradictory information by people applying different weights to sometimes competing values." ${ }^{38}$ This makes ethics in floods complicated and challenging. Gathering and organizing the ethical issues in this review here is one step toward linking the existing social and economic inequalities, vulnerabilities, and resilience with planning and actions that can prevent or reduce the costs, harms, and numbers of victims in floods. ${ }^{21}$ The way forward is challenging, but the alternative is less attractive because "ethically unsound decisions can produce disastrous results not only for those already living in precarious situations, but also for those endeavoring to assist them., ${ }^{29}$ Further conceptual analysis can help clarify the ethical issues, but such research must lead to clear and practical guidance and decision-making tools. Our hope is that this review will alert readers to the intimate link between ethics and floods, and stimulate further scholarship and practical action on this topic.

\section{CONCLUSION}

This systematic review had limitations. The search was restricted to 4 electronic databases, which included academic literature primarily, although from a wide variety of fields. Grey literature was not searched, which could provide relevant material from international organizations (like the Intergovernmental Panel on Climate Change [IPCC] or the United Nations International Strategy for Disaster Reduction [UNISDR]) and nongovernmental organizations. Likewise, news media and books were not reviewed. Additional or different ethical issues might be discussed outside of academic sources. However, the scale of such a broad search went beyond the resources available for this review. Another limitation was that most publications were qualitative and presented personal views as opposed to empirical studies. This prevents any clear conclusions about the scale of ethical issues and the extent of their impact. Such studies should be undertaken to better understand these dimensions. In addition, the qualitative nature of this review's analysis means that the authors' professional and personal orientations may have influenced the selection of articles and the identification and classification of themes and subthemes. Such limitations are inherent to this type of research, and mean that caution is required in generalizing any of the findings.

Nonetheless, this systematic review reveals a wide variety of ethical issues and situations in floods. The results have implications for those involved in DRR and flood risk management, showing that ethical issues should be considered carefully in planning for and responding to floods. Given the variety of ethical issues identified, an interdisciplinary approach is required to ensure that ethics is considered at all stages of flood planning and responding. Research is needed into the scale and experience of ethical issues in floods, so that evidencebased approaches to ethics in floods are developed and implemented. Only then can some assurance be provided that floods are addressed in the right way at the right time.

\section{About the Authors}

University of Belgrade, Faculty of Philosophy, Belgrade, Serbia (Dr Mitrović); School of Nursing and Human Sciences, Dublin City University, Ireland; College of Nursing, The Ohio State University, Columbus, Ohio, USA (Dr O'Mathúna); and University of Zagreb, School of Medicine, Andrija Stampar School of Public Health, Zagreb, Croatia (Dr Nola).

Correspondence and reprint requests to Iskra A. Nola, University of Zagreb, School of Medicine, Andrija Stampar School of Public Health, Rockefeller Street 4, Zagreb, Croatia (e-mail: ianola@snz.hr)

\section{Acknowledgments}

The authors acknowledge the support of COST Action IS1201: Disaster Bioethics (http://DisasterBioethics.eu), which funded short-term scientific missions (STSMs) at the Universities of Zagreb and Belgrade and attendance at Action events where this paper was developed.

\section{Conflict of Interest Statement}

The authors declare no conflicts of interest.

\section{REFERENCES}

1. Frodeman R, Klein JT, Mitcham C, Tuana N. Introduction: new directions/cities and rivers: interdisciplinary studies in knowledge production. Nat Cult, 2007;2(2):176-187.

2. O'Mathúna DP, Gordijn B, Clarke M, eds. Disaster Bioeth, Dordrecht: Springer; 2014.

3. Karadag CO, Hakan AK. Ethical dilemmas in disaster medicine. Iran Red Crescent Med J, 2012;14(10):602-612.

4. Zack N. The ethics of disaster planning: preparation vs response. Philos Manag, 2009;8(2):55-66.

5. Moatty A. Post-flood recovery: an opportunity for disaster risk reduction? In: Vinet F, ed. Floods. Volume 2 - Risk Management. London: ISTE Press and Elsevier; 2017:349-363.

6. Neslen A. Flood disasters more than double across Europe in 35 years. The Guardian. https://www.theguardian.com/environment/2017/jan/19/ flood-disasters-more-than-double-across-europe-in-35-years. Published January 19, 2017. Accessed June 1, 2018. 
7. Wallemacq P. Natural disasters in 2017: lower mortality, higher cost. Cred Crunch 50:1-2. https://www.cred.be/publications. Published March 31, 2018. Accessed June 1, 2018.

8. Macpherson CC, Akpinar-Elci M. Caribbean heat threatens health, well-being and the future of humanity. Public Health Ethics, 2015;8 (2):196-208.

9. Moatty A, Vinet F. Post-disaster recovery: the challenge of anticipation. E3S Web Conf, 2016;7:17003.

10. Mariaselvam S, Gopichandran V. The Chennai floods of 2015: urgent need for ethical disaster management guidelines. Ind J Med Ethics, 2016;1 (2):91-95.

11. Alderman K, Turner LR, Tong S. Floods and human health: a systematic review. Environ Int, 2012;47:37-47.

12. Zack N. Ethics for Disaster. Lanham, MD: Rowman \& Littlefield; 2009.

13. Simpson AV, Cunha MP, Clegg S. Hybridity, sociomateriality and compassion: what happens when a river floods and a city's organizations respond? Scand J Manag, 2015;31:375-386.

14. Rich TP. Lessons in social responsibility from the Austin Dam failure. Int J Eng Edu, 2006;22(6):1287-1296.

15. Hvistendahl M. China's three gorges dam: an environmental catastrophe? Scientific American. https://www.scientificamerican.com/article/chinas-three-gorges-dam-disaster. Published March 25, 2008. Accessed June 1, 2018.

16. Chacowry A. Public perceptions of living with flood risk from media coverage in the small island developing state of Mauritius. Int J Disaster Risk Reduct, 2016;19:303-310.

17. Morss RE, Wahl E. An ethical analysis of hydrometeorological prediction and decision making: the case of the 1997 Red River flood. Environ Haz, 2007;7:342-352.

18. Rossano F. From absolute protection to controlled disaster: new perspectives on flood management in times of climate change. J Landsc Archit, 2015;10(1):16-25.

19. Newberry B. Katrina: macro-ethical issues for engineers. Sci Eng Ethics, 2010;16:535-571.

20. Jurkiewicz CL. Political leadership, cultural ethics and recovery: Louisiana post-Katrina. Public Organ Rev, 2009;9:353-366.

21. Mitrović VL. Resilience: detecting vulnerability in marginal groups. Disaster Prev Manag, 2015;24(2):185-200.

22. Moher D, Liberati A, Tetzlaff J, Altman DG, The PRISMA Group. Preferred reporting items for systematic reviews and meta-analyses: the PRISMA statement. PLoS Med. 2009;6(6):e1000097.

23. Srinivasan S. After the floods: health services' responsibilities in a crisis. Ind J Med Ethics. 2005;2(4):108-109.

24. Keays JF. The ethical position of the engineering profession. In: January 1974 floods, Moreton region: Proceedings of Symposium. Australia: Institute of Engineers; 1974:272-273.

25. Gaitonde R, Gopichandran V. The Chennai floods of 2015 and the health system response. Ind J Med Ethics, 2016;1(2):71-75.

26. Jurkiewicz CL. Louisiana's ethical culture and its effect on the administrative failures following Katrina. Public Admin Rev, 2007;67: $57-63$.

27. Ewart J, McLean H. Ducking for cover in the "blame game": news framing of the findings of two reports into the 2010-11 Queensland floods. Disasters. 2015;39(1):166-184.

28. Rizza C, Pereira ÂG. Building a resilient community through social network: ethical considerations about the 2011 Genoa floods. In: Hiltz SR, Pfaff MS, Plotnick L, Shih PC, eds. Proceedings of the 11th International ISCRAM. 2014:289-293.

29. Johnston D. An examination of the principles-based ethics by which Red Cross personnel evaluate private donor suitability. In: Beard M, Lynch S, eds. Conscience, Leadership and the Problem of "Dirty Hands." Res Ethics Iss Organ. Bingley, UK: Emerald; 2015;13:119-137.
30. de Groot M. Exploring the relationship between public environmental ethics and river flood policies in western Europe. J Environ Manag, 2012;93(1):1-9.

31. Lane SN. Ethical risk management, but without risk communication? In: Kearnes M, Klauser F, Lane S. Critical Risk Research: Practices, Politics and Ethics. Oxford, UK: Wiley; 2012:151-172.

32. Parkash S. Ethics in disaster management. Ann Geophys, 2012;55 (3):383-387.

33. Malik AM. Denial of flood aid to members of the Ahmadiyya Muslim community in Pakistan. Health Hum Rights. 2011;13(1):62-69.

34. Holt WG. Do you know what it means to rebuild New Orleans? Cultural sustainability after disaster. In: Holt WG, ed. Research in Urban Sociology. From Sustainable to Resilient Cities: Global Concerns and Urban Efforts. UK: Emerald; 2014;14:267-287.

35. Li R, Van Beek E, Gijsberg P. Integrated water resources management for the Yellow River in China: a discussion of scientific and ethical approaches. The Basis of civilization - water science? (Proceedings of the UNESCO/IAIIS/IWTIA symposium held in Rome. December 2003). IAHS. 2004;286:150-159.

36. Glantz M, Jamieson D. Societal response to Hurricane Mitch and intraversus intergenerational equity issues: whose norms should apply? Risk Anal, 2000;20(6):869-882.

37. Hugo G. Environmental concerns and international migration. Int Migr Rev. 1996;30(1):105-131.

38. Fahey CJ. Ethics and disasters: mapping the moral territory. Generation. 2007:61-65.

39. Wildes KW. An ethicist's perspective. Chronicle of Higher Education. https://www.chronicle.com/article/An-Ethicists-Perspective/5867. Published April 21, 2006. Accessed June 1, 2018.

40. Daniel DE. A perspective on the levee failures in New Orleans from Hurricane Katrina. Geotech Spec Publ, 2014;233:271-282.

41. Dennis MR, Kunkel AD, Woods G, Schrodt P. Making sense of New Orleans flood trauma recovery: ethics, research design, and policy considerations for future disasters. Anal Soc Iss Public Policy, 2006;6 (1):191-213

42. Zegwaard A, Petersen AC, Wester P. Climate change and ontological politics in the Dutch Delta. Clim Change, 2015;132:433-444.

43. Clark MJ. Putting water in its place: a perspective on GIS in hydrology and water management. Hydrol Process, 1998;12:823-834.

44. Breo DL. Flood, sweat, and tears - trying to build "emotional levees." $J$ Am Med Assoc, 1993;270(23):2860-2862.

45. Takahashi T. Ethics of natural disasters: Tanaka Shozo and the Ashio Mine poisoning. Tamkang Rev, 2006;37(1):159-169

46. Simonovic SP. Two new floods, climate change, and ethics. J Flood Risk Manag, 2011;4:141-142.

47. Botez C. Liquefactions: river floods and tides of memory in Anne Michaels' Fugitive Pieces. Soc Altern, 2014;33(2):23-31.

48. Tsu TYH. Making virtues of disaster: "Beautiful Tales" from the Kobe Flood of 1938. Asian Stud Rev, 2008;32(2):197-214.

49. Bergstrom S. Principles and confidence in hydrological modelling. Hydro Res, 1991;22:123-136.

50. Mezinska S, Kakuk P, Mijaljica G, et al. Research in disaster settings: a systematic qualitative review of ethical guidelines. BMC Med Ethics, 2016;17(1):1-11.

51. Zack N. Violence, poverty, and disaster: New Orleans, Haiti, and Chile. Radic Philos Rev, 2012;15(1):53-65.

52. Lewis J. Some realities of resilience: an updated case study of storms and flooding at Chiswell, Dorset. Disaster Prev Manag, 2013;22 (4):300-311.

53. Barton AH. Disaster and collective stress. In: Perry RW, Quarantelli EL, eds. What Is a Disaster? New Answers to Old Questions. USA: International Research Committee on Disasters; 2005:125-153. 